\title{
Association of environmental risk factors and trachoma in Gashoho Health District, Burundi
}

\author{
Desire Ndisabiye $^{1}$, Athanase Gahungu ${ }^{2}$, Donatien Kayugi ${ }^{2}$, Edward K Waters ${ }^{1}$
}

1. School of Medicine, University of Notre Dame Australia, 160 Oxford St Darlinghurst NSW 2010 Australia.

2. National Integrated Program for Neglected Tropical Diseases, Ministry of Health, Rue Pierre

Ngendandumwe, Bujumbura, Burundi.

\section{Contact details for other authors:}

Athanase Gahungu: gathanase@ymail.com; Donatien Kayugi drakayugi@yahoo.fr; Edward K Waters: edward.waters@nd.edu.au

\begin{abstract}
Background: Burundi is currently not meeting targets for elimination of trachoma and trichiasis by 2020 (GET2020). The recommended SAFE strategy (Surgery, antibiotics, face washing and environmental improvement) is currently not fully implemented in many areas of Burundi. The existence of associations between face-washing, sanitation and trachoma prevalence remain undocumented.

Methods: A convenience sample of 468 individuals from 117 households was drawn from attendees at trachoma clinics set up in four villages. Trachoma status, sex and age were recorded for all household members. Adult household members were surveyed about access to clean water and toilets, and knowledge of trachoma risk factors. Associations between cases of active trachoma per household and environmental risk factors were evaluated using generalised estimating equations.

Results: The overall prevalence of active trachoma was 7.1\% (95\% CI 5.0-9.6\%), but 19.5\% (95\% CI13.7-26.4\%) in children under nine years old. $0.9 \%$ (95\% CI 0.3-2.0) of participants had trichiasis. Access to a sanitary toilet more than halved the odds of active trachoma (OR $0.43,95 \%$ CI $0.25-0.74 \%$ ), however, participants did not appreciate this association.

Conclusion: Access to sanitation was associated with the occurrence of active trachoma. Future research should focus on whether improving knowledge of and access to sanitation might reduce trachoma prevalence.

Keywords: Environmental risk factors, trachoma, Gashoho Health District, Burundi.

DOI: https://dx.doi.org/10.4314/ahs.v20i1.23

Cite as: Ndisabiye D, Gahungu A, Kayugi D, Waters EK. Association of environmental risk factors and trachoma in Gashoho Health District, Burundi. Afri Health Sci. 2020;20(1):182-9. bttps:/ / dx.doi.org/10.4314/abs.v20i1.23
\end{abstract}

\section{Introduction}

Trachoma is an infectious disease caused by the bacterium Chlamydia trachomatis ${ }^{1,2,3}$. Repeated experiences of acute trachoma infection in childhood can eventually lead to irreversible inflammation ${ }^{4,5,6}$. If untreated, this inflam-
Corresponding author:
Desire Ndisabiye,
School of Medicine, University of Notre
Dame Australia
160 Oxford St Darlinghurst NSW 2010
Australia
Tel +61 426903000
Email: desire.ndisabiye1@my.nd.edu.au

mation can progress to scarring (trichiasis), which can in turn lead to blindness ${ }^{6}$. In common parlance, the acutely infectious stages of the disease are called "active trachoma"7, and these can be treated by antibiotics. The sequelae of scarring and blindness are commonly referred to as "irreversible trachoma", and require surgical management. The World Health Organisation (WHO) has as a target the global elimination of trachoma by 2020 (GET2020) by achieving global reductions in the prevalence of follicular trachomatous inflammation ${ }^{9,10}$, the first result of repeated $C$. trachomatis infection, in children aged 1-9 years old to $<5 \%$ in all endemic regions by $2020^{10}$. The second target is to surgically treat the 10 million individuals at risk of blindness due to trichiasis. As cited.
} 
of 2018, many African countries, including Burundi, are not on track to meet these targets.

The endemic nature of trachoma transmission in Africa is facilitated by the presence of environmental risk factors that are common in the developing world. A scarcity of clean water is suspected to promote trachoma transmission, because less water is available to use for cleaning the face of infectious secretions ${ }^{11,12}$. Similarly, limited access to sanitation increases faecal contamination of the environment, therefore promoting breeding of the fly Musca sorbens, which is a vector for trachoma ${ }^{13,14}$. The important role of these environmental factors in transmission is reflected in the SAFE strategy promoted by the WHO as a means of achieving GET 2020. The SAFE strategy comprises: surgery for trichiasis $(\mathrm{S})$, antibiotics $(\mathrm{A})$, and promotion of face-washing $(\mathrm{F})$ and environmental improvements (E) to suppress transmission.

In Burundi, as in some other African countries, only the "antibiotics" component of the SAFE strategy has been systematically implemented ${ }^{15,16}$. Measures for increasing face-washing or environmental improvement have been neglected, in part because of the low-quality evidence from peer reviewed literature regarding the magnitude of the association between these risk factors and trachoma prevalence ${ }^{16}$. Increased attention is being given to these components of the SAFE strategy as the current approach has not achieved the elimination targets.

The need for a better coordinated implementation and evaluation of the SAFE strategy in Burundi has been examined by a number of local research studies ${ }^{17,18}$. Despite azithromycin distribution to $91 \%$ of individuals in endemic regions ${ }^{18,11}$ districts in Burundi still have endemic levels of active trachoma. These districts are identified by the WHO as requiring full implementation of the SAFE strategy to achieve their GET2020 $\operatorname{targets}^{16}$, despite the effect size associated with the $\mathrm{F}$ and $\mathrm{E}$ components being poorly understood. Gashoho Health District, where this study is situated, is one of these 11 districts. Despite being located in Muyinga province, which was targeted for mass azithromycin distribution from 2010-2014 ${ }^{18}$, trachoma remains endemic in Gashoho. Therefore, this study investigates whether the frequency of face-washing and improvements in sanitation are associated with active tra- choma in four communities of Gashoho health district.

\section{Methods}

\section{Study design}

This is a cross sectional study to investigate the relationship between environmental risks factors and the prevalence of trachoma, using convenience samples from four clinics in the Gashoho health district. The method of Walter et al. ${ }^{19}$ was used to calculate the sample size required for specified levels of the type I and type II error. A minimum sample size of 350 individuals across 4 villages was required to detect moderate differences in prevalence with $5 \%$ precision (type I error) and $80 \%$ power (1 - type II error). Community members were informed of the location of the clinic by the local town crier/ drum man, which is a common means of transmitting messages in African communities that do not have universal radio, television, internet or newspaper access ${ }^{20}$. The study was carried out in April during the Easter school holidays, when school aged children could attend the clinics. April falls during the wet season in Burundi, and is warm and humid with most of the year's rain (1.2 $\mathrm{m}$ on average) falling during the wet season. Attendees at the clinics were invited to participate in the study. Participant information was provided in the local language Kirundi; it was emphasised that participation in the study did not influence access to the care offered by the clinics. Each participant aged over 18 years was responsible for providing their own consent. Where adults attended with children in their care, they were asked to provide consent for their children's clinical data to be included in the study.

The field survey received ethical approval from the Gashoho Health District, Neglected Tropical Diseases Program, and the University of Notre Dame Australia (HREC Approval Number 017167S).

\section{Study location}

The health district of Gashoho is located in the middle of the province of Muyinga, north Burundi (see Figure 1). The population of Burundi is estimated at $11,400,379$ people, of whom $87 \%$ live in rural villages, similar to the study sites. $50.8 \%$ of the population are female, and $49 \%$ of the population is aged under 15 years of age.(20) $83 \%$ have access to clean water, but only $39 \%$ of the population have access to sanitary toilets. ${ }^{21}$ 


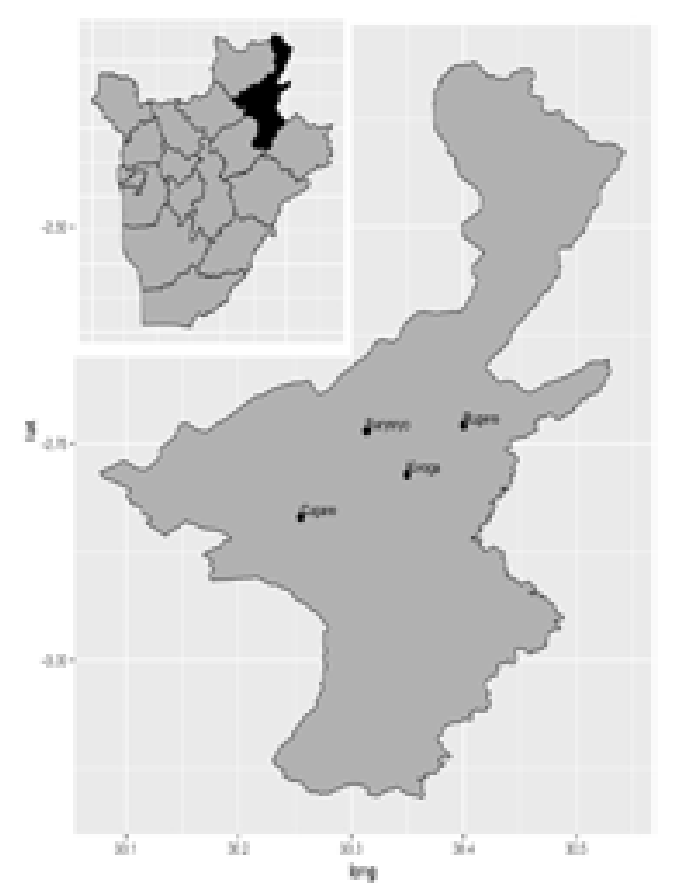

Figure 1 Main map: the location of the four villages in the province of Muyinga. Inset: the location of the Muyinga province in Burundi.

\section{Data collection}

Data was collected in clinics established in the four villages as part of the normal work of the National Integrated Neglected Tropical Diseases Blindness Program and Health District's Trachoma control initiative. The clinical investigators (AG and DK) set up clinics to offer trachoma screening according WHO guidelines in the four villages within the Health District: Kivoga and Rugero (Gashoho council area), and Cugaro and Buryoryo (Gasorwe council area). All individuals who attended the clinics consented to participate in the study. They received the standard clinical management provided in all trachoma clinics run by the district. Participants were examined clinically for the presence of trachoma and its clinical stage, and if found to have active trachoma (inflammatory or follicular stages), were prescribed antibiotics by a single dose of azithromycin at a dose of $20 \mathrm{mg} / \mathrm{kg}$ for children and of $1 \mathrm{~g}$ for adult as recommended by WHO. Individuals with trichiasis or cornea opacity (called irreversible trachoma) were referred for surgery. Those individuals who agreed to participation in the study had their infectious status, age, and sex recorded. Infectious status is defined as the presence of clinical trachoma, based on the assumption that individuals with ocular secretions have the capacity to transmit trachoma.

In addition, the adults from each household were surveyed to assess their knowledge about the importance of face-washing and sanitation in transmitting trachoma. The survey form is provided in supplementary material. In addition: the composition of each household, its access and proximity to clean water, and its access to sanitary toilet facilities was recorded. Clean water was defined as piped water to a yard, access to a public tap or standpipe, a household tube well or a bore hole, or a protected dug well. Sanitary toilets were defined as a flush toilet, a piped sewer, septic tank, ventilated pit latrine, or a pit latrine with slab. No information was collected on the density of flies during the time period of the study, because the literature does not suggest a clear association between time and the abundance of this vector in the study location. ${ }^{23}$

\section{Data analysis}

Differences in the prevalence of binary trachoma risk factors (gender, household access to improved water, household access to improved toilets) and active or irreversible trachoma between villages and districts were analysed using chi square. Differences in demographics (mean household age, mean household size, mean proportion of the population below 9 years of age, distance to clean water) between villages and districts were analysed using one-way ANOVA. Responses to survey questions about knowledge of trachoma were analysed using descriptive statistics.

Generalised estimating equations (GEE) were used for analysis of the association between risk factors and ac- 
tive trachoma per individual per household, since the infectious status of individuals who lived within the same household was correlated with risk factors at the household level (access to clean water or toilets). To conduct the analysis in SPSS, household was set as the subject level variable, and each individual within the household was set as the within subject variable.

The initial GEE model included individuals' age, household distance to clean water, household access to improved water, and household access to improved toilet facilities as independent variables and active trachoma (any, or none) as the dependent variable was used to determine the association between these predictors and active trachoma in any member of a household. Individuals with irreversible trachoma (trichiasis or corneal opacity) were excluded from the analysis. A logistic link function was used because of the binary nature of the dependent variable. All two-way interactions were included in the initial model, and backwards elimination was used to remove non-significant variables stepwise.

SPSS version 25.0 for Mac OSX (IBM, Armonk, New York) was used for the analysis and difference was considered as statistically significant at $\mathrm{p}$ value $<0.05$.

\section{Results}

Four hundred sixty eight individuals from 117 households attended the clinics, and all consented to participate in the study. The number of households and individuals surveyed in each village is given in Table 1.

There were no significant demographic differences between villages. The average age of participants for the four villages was 21.10 with a standard deviation (SD) of 0.78 . The proportion of participants under 9 years old in total was $34.8 \%$ with a CI confidence interval (30.639.2). Males and females equally participated in our study. These results are summarised in Table 1.

Table 1 Characteristics of the sample drawn from each village

\begin{tabular}{|l|l|l|l|l|l|}
\hline & Buryoryo & Cugaro & Kivoga & Rugero & Overall \\
\hline $\begin{array}{l}\text { Age } \\
\text { Mean (SD) }\end{array}$ & $19.30(1.31)$ & $23.69(1.84)$ & $19.46(1.34)$ & $22.48(1.74)$ & $21.10(0.78)$ \\
\hline $\begin{array}{l}\text { <9 y.o. } \\
\text { Proportion } \\
(95 \% \text { CI) }\end{array}$ & $\begin{array}{l}39.3(30.8- \\
48.3)\end{array}$ & $\begin{array}{l}30.7 \%(22.3- \\
40.1)\end{array}$ & $\begin{array}{l}35.1 \% \\
(27.3-43.5)\end{array}$ & $\begin{array}{l}33.6 \%(25.6- \\
42.4)\end{array}$ & $\begin{array}{l}34.8 \%(30.6- \\
39.2)\end{array}$ \\
\hline $\begin{array}{l}\text { Gender } \\
\text { M (53.0\%) }\end{array}$ & $\begin{array}{l}\mathrm{M}(48.5 \%) \\
\mathrm{F}(51.5)\end{array}$ & $\begin{array}{l}\mathrm{M}(48.9) \\
\mathrm{F}(51.1)\end{array}$ & $\begin{array}{l}\mathrm{M}(49.6 \%) \\
\mathrm{F}(50.4 \%)\end{array}$ & $\begin{array}{l}\mathrm{M}(50 \%) \\
\mathrm{F}(50 \%)\end{array}$ \\
\hline $\begin{array}{l}\text { Household } \\
\text { size } \\
\text { (Median and } \\
\text { range) }\end{array}$ & $4(2-9)$ & $5(2-8)$ & $6(3-12)$ & $5(2-10)$ & $5(2-12)$ \\
\hline $\begin{array}{l}\text { Number of } \\
\text { household }\end{array}$ & 30 & 25 & 25 & 27 & 117 \\
\hline $\begin{array}{l}\text { Number of } \\
\text { individuals }\end{array}$ & 117 & 101 & 131 & 119 & 468 \\
\hline
\end{tabular}

The overall prevalence of any trachoma in the sample was estimated at $7.9 \%, 7.1 \%$ of which was active trachoma (see Table 2). In children under nine years old the prevalence was $19.5 \%$. Most active trachoma was inflammatory rather than follicular. The prevalence of corneal opacity or trichiasis was $0.9 \%$ overall but Kivoga had zero cases, whilst Buryoryo had a prevalence of $1.7 \%$ There were no significant differences between villages in any of these estimates.
There was no statistically significant difference in the proportion of households that had access to clean water or toilets (see Table 2), however, the mean distance to clean water (for households that had access) significantly differed between villages $(p<.001)$, with distances varying from 150 to 500 meters. Overall, $73.8 \%$ of surveyed household and $74.3 \%$ surveyed individuals reported no access to improved toilets. An average of $58.9 \%$ (95\% CI 49.4-67.9\%) of household reported no access to clean water. 
Table 2 Percentage $(95 \% \mathrm{CI})$ of people with trachoma and without access to clean water or sanitation.

\begin{tabular}{|l|l|l|l|l|l|}
\hline & Buryoryo & Cugaro & Kivoga & Rugero & Overall \\
\hline Any trachoma & $\begin{array}{l}8.5 \\
(4.5-14.6)\end{array}$ & $\begin{array}{l}8.9(4.5- \\
15.6)\end{array}$ & $\begin{array}{l}7.6(4.0- \\
13.1)\end{array}$ & $\begin{array}{l}6.7(3.2- \\
12.3)\end{array}$ & $\begin{array}{l}7.9(5.0- \\
10.6)\end{array}$ \\
\hline $\begin{array}{l}\text { Active } \\
\text { trachoma }\end{array}$ & $\begin{array}{l}6.8(3.3- \\
12.5)\end{array}$ & $\begin{array}{l}7.9(3.8- \\
14.4)\end{array}$ & $\begin{array}{l}7.6(4.0- \\
13.1)\end{array}$ & $\begin{array}{l}5.9(2.7- \\
11.2)\end{array}$ & $\begin{array}{l}7.1(5.0- \\
9.6)\end{array}$ \\
\hline $\begin{array}{l}\text { Corneal } \\
\text { opacity or } \\
\text { trichiasis }\end{array}$ & $1.7(0.4-5.4)$ & $1(0.1-4.5)$ & 0.0 & $0.8(0.1-3.9)$ & $\begin{array}{l}0.9(0.3- \\
2.0)\end{array}$ \\
\hline $\begin{array}{l}\text { Active } \\
\text { trachoma }(<9 . \\
\text { y.o. })\end{array}$ & $\begin{array}{l}17.1(8.0- \\
30.6)\end{array}$ & $\begin{array}{l}24.1(11.5- \\
41.6)\end{array}$ & $\begin{array}{l}19.5(9.7- \\
33.5)\end{array}$ & $\begin{array}{l}18.5(8.6- \\
32.8)\end{array}$ & $\begin{array}{l}19.5(13.7- \\
26.4)\end{array}$ \\
\hline $\begin{array}{l}\text { Inflammatory } \\
\text { trachoma }(<9 \\
\text { y.o. })\end{array}$ & $\begin{array}{l}12.2 \\
(4.8-24.7)\end{array}$ & $\begin{array}{l}17.2 \\
(6.9-33.7)\end{array}$ & $\begin{array}{l}14.6 \\
(6.3-27.7)\end{array}$ & $\begin{array}{l}13.2 \\
(5.2-26.5)\end{array}$ & $\begin{array}{l}14.1 \\
(9.2-20.4)\end{array}$ \\
\hline $\begin{array}{l}\text { Follicular } \\
\text { trachoma }(<9 \\
\text { y.o. })\end{array}$ & $\begin{array}{l}4.9 \\
(1.0-14.9)\end{array}$ & $\begin{array}{l}6.9 \\
(1.5-20.3)\end{array}$ & $\begin{array}{l}4.9 \\
(1.0-14.7)\end{array}$ & $\begin{array}{l}5.3 \\
(1.1-15.8)\end{array}$ & $\begin{array}{l}5.4 \\
(2.6-9.9)\end{array}$ \\
\hline $\begin{array}{l}\text { No access to } \\
\text { sanitary toilets }\end{array}$ & $\begin{array}{l}70.0(52.3- \\
84.0)\end{array}$ & $\begin{array}{l}84.0(66.3- \\
94.3)\end{array}$ & $\begin{array}{l}68.0(48.5- \\
83.6)\end{array}$ & $\begin{array}{l}74.1(55.7- \\
87.6)\end{array}$ & $\begin{array}{l}73.8(64.9- \\
81.4)\end{array}$ \\
\hline $\begin{array}{l}\text { No access } \\
\text { improved } \\
\text { water }\end{array}$ & $\begin{array}{l}50.0(32.8- \\
67.2)\end{array}$ & $\begin{array}{l}72.0(52.7- \\
86.5)\end{array}$ & $\begin{array}{l}60.0(40.6- \\
77.3)\end{array}$ & $\begin{array}{l}55.6(37.1- \\
72.9)\end{array}$ & $\begin{array}{l}58.9(49.4- \\
67.9)\end{array}$ \\
\hline
\end{tabular}

All of adults agreed or strongly agreed that frequent face washing was important in reducing the risks of trachoma. However, none of them identified sanitation as being associated with trachoma transmission.

In the final GEE model, only an individual's age and the household's access to sanitary toilet facilities were significant predictors of active trachoma in any household member (see Table 3). Access to a sanitary toilet more than halved the odds of an individual within the household having trachoma, making this the most significant modifiable risk factor for active trachoma.

Table 3 Significant predictors of trachoma infection in the final model.

\begin{tabular}{|l|l|l|l|}
\hline & P value & OR & $95 \%$ CI \\
\hline Age & 0.004 & 0.918 & $0.866-0.972$ \\
\hline $\begin{array}{l}\text { Access to } \\
\text { sanitary toilet }\end{array}$ & 0.002 & 0.437 & $0.256-0.743$ \\
\hline
\end{tabular}




\section{Discussion}

The results of this study showed that trachoma remains a public health issue in the remote community of Gashoho health district. The prevalence of active trachoma in Gashoho remains over the GET2020 target of 5\% required for elimination. The overall prevalence of $7.9 \%$ (95\% CI 5.0-10.6 \%) was not significantly different from the previously reported prevalence, ${ }^{16}$ suggesting the representativeness of our sample. In some villages, about $1 \%$ of individuals had corneal opacity or blindness. These findings are practically unchanged from those reported in $2011^{17}$. Children aged under nine years were important drivers of transmission, with the prevalence of active trachoma in this group being $19.5 \%$, with most cases being the more infectious inflammatory stage (see Table 2). This is also reflected in the protective association between increasing age and active trachoma (OR 0.918 for each additional year of age). These findings are similar to those previously reported ${ }^{18}$, and reflect the underlying natural history of disease, which consists of repeated episodes of active trachoma during childhood and the accumulation of scar tissue leading to potential blindness in adulthood. ${ }^{6}$

It has been suggested that further reductions in trachoma prevalence in Burundi depends on emphasising face-washing and environmental improvements, including sanitation ${ }^{18}$. In Gashoho health district, we found evidence that there was knowledge of the importance of face-washing, but access to clean water was not associated with an increased risk of active trachoma. This result may reflect the knowledge-based motivation of villagers to maintain good facial hygiene even where access to water is difficult. On the other hand, villagers had very poor knowledge about the role of sanitation in preventing the spread of trachoma, but the most significant predictor of trachoma status in our sample was access to sanitation. Individuals living in households with access to sanitary toilet facilities more than halved their risk of active trachoma. Access to an improved toilet, unlike face-washing, does not require behaviour modification; people will use them if they are available. This may explain why access to improved toilets led to a significantly reduced risk of active trachoma in our sample, even in the absence of knowledge about poor sanitation being a risk factor. Further research is required to establish whether this association may have implications for trachoma control.

These results taken together indicate that whilst there are high levels of awareness of the importance of face-washing in Gashoho Health District, and this may have ameliorated the risks associated with poor access to clean water, there is substantial room to improve the population's knowledge about the role of environmental sanitation in reducing the risk of experiencing active trachoma. Access to sanitation significantly reduces the risk of active trachoma even in the absence of improved knowledge. Future efforts at controlling trachoma in the Gashoho health district should focus on improving sanitation, which reduces trachoma transmission by eliminating breeding grounds forlies. The large effect size associated with access to improved toilets shown in our study suggests that targeting this risk factor might be associated with a significant reduction in the risk of active trachoma. Importantly, the proportion of individuals in our sample without access to sanitary toilets was similar to the national average of $39 \%,{ }^{21}$ suggesting that the results of this study have implications for Burundi as a whole. In future research, we will employ mathematical models to investigate how much reduction in trachoma incidence might be associated with improved sanitation and whether focusing on environmental improvement alone might be sufficient to reduce the prevalence of trachoma to the less than 5\% target required for elimination.

There were a number of limitations in this study. First, whilst the study included four villages and two council areas to try to improve generalisability, it is possible that the four villages surveyed may not be representative of the rest of Burundi with respect to trachoma prevalence and risk factors. However, the prevalence of trachoma in these villages was similar to that reported in studies across Burundi previously; ${ }^{16}$ this suggests that the findings of this study are similar to other areas of the country. A second limitation relates to the timing of the survey; it is possible that the effect size associated with poor sanitation might be different in the dry season from the wet season. However, the main mode of transmission associated with poor sanitation is likely to be vector borne transmission (flies). Flies would become more active during the dry season, potentially increasing the association between poor sanitation and infectious status. Future studies in the dry season should be conducted to examine this hypothesis.

Finally, the study was limited because the relationship between improved toilets and trachoma status depended 
on self-reported data. It would have been desirable for surveyors to obtain information on sanitation and access to clean water by visiting households. Unfortunately, financial constraints made this impossible, as it would have required the employment of more research staff for a longer time. Future research should validate our findings by more in depth observations in the field.

\section{Conclusion}

The prevalence of trachoma in Gashoho health District is estimated at around $8 \%$ and access to clean water and sanitary toilet facilities are lacking. Poor access to sanitary toilet facilities was the most significant modifiable risk factor identified in this study. Efforts to eliminate trachoma in Gashoho health district should focus on improving sanitation, but also on providing information about the possible importance of sanitation in preventing transmission, as this knowledge was lacking in the sample surveyed.

\section{Acknowledgements}

This study was partially funded by a grant from the School of Medicine, University of Notre Dame Australia.

\section{Conflicts of interest}

None to declare.

\section{References}

1. Becker Y. The chlamydia: molecular biology of procaryotic obligate parasites of eucaryocytes. Microbiol Rev. 1978;42(2):274-306.

2. Macleod CK, Butcher R, Mudaliar U, Natutusau K, Pavluck AL, Willis R, et al. Low Prevalence of Ocular Chlamydia trachomatis Infection and Active Trachoma in the Western Division of Fiji. PLoS Negl Trop Dis. 2016;10(7):1-12.

3. Mabey DCW, Solomon AW, Foster A. Trachoma. 2003;362:223-9.

4. Burton M, Habtamu E, Ho D, Gower EW. Interventions for trachoma trichiasis. Cochrane Database Syst Rev. 2015;2015(11).

5. Alexei Ivanov JOF. Towards elimination of blinding trachoma in Burkina Faso, West Africa. The results of three consecutive years of mass antibiotic treatment and health education. Fac Med Univ Oslo, Norw. 2014;(October):1-31.

6. Grassly NC, Ward ME, Ferris S, Mabey DC, Bailey RL. The natural history of trachoma infection and dis- ease in a Gambian cohort with frequent follow-up. PLoS Neglected Tropical Diseases. 2008 Dec 2;2(12):e341.

7. Last AR, Burr SE, Weiss HA, Harding-Esch EM, Cassama E, Nabicassa M, Mabey DC, Holland MJ, Bailey RL. Risk factors for active trachoma and ocular Chlamydia trachomatis infection in treatment-naïve trachoma-hyperendemic communities of the Bijagós Archipelago, Guinea Bissau. PLoS Neglected Tropical Diseases. 2014 Jun 26;8(6):e2900.

8. Dawson CR, Jones BR, Darougar S. Blinding and non-blinding trachoma: assessment of intensity of upper tarsal inflammatory disease and disabling lesions. Bulletin of the World Health Organization. 1975;52(3):279.

9. Sanders AM, Stewart AEP, Mayo S, Chebet JJ, Magok P, Kuol A, et al. Burden of trachoma in five counties of Eastern Equatoria state, South Sudan: Results from population-based surveys. PLoS Negl Trop Dis. 2017;11(6):115.

10. Emerson PM, Burton M, Solomon AW, Bailey R, Mabey D. The SAFE strategy for trachoma control: Using operational research for policy, planning and implementation. Bull World Health Organ. 2006;84(8):613-9.

11. Schémann JF, Sacko D, Malvy D, Momo G, Traore $\mathrm{L}$, Bore $\mathrm{O}$, et al. Risk factors for trachoma in Mali. Int J Epidemiol. 2002;31(1):194-201.

12. Last AR, Burr SE, Weiss HA, Harding-Esch EM, Cassama E, Nabicassa M, et al. Risk Factors for Active Trachoma and Ocular Chlamydia trachomatis Infection in Treatment-Naïve Trachoma-Hyperendemic Communities of the Bijagós Archipelago, Guinea Bissau. PLoS Negl Trop Dis. 2014;8(6).

13. Ngondi J, Matthews F, Reacher M, Baba S, Brayne C, Emerson P. Associations between active trachoma and community intervention with antibiotics, facial cleanliness, and environmental improvement (A,F,E). PLoS Negl Trop Dis. 2008;2(4).

14. Ko R, Macleod C, Pahau D, Sokana O, Keys D, Burnett A, et al. Population-Based Trachoma Mapping in Six Evaluation Units of Papua New Guinea. Ophthalmic Epidemiol [Internet]. 2016;23(1):22-31. Available from: http:/ /dx.doi.org/10.1080/09286586.2016.1235715 15. Delea MG, Solomon H, Solomon AW, Freeman MC. Interventions to maximize facial cleanliness and achieve environmental improvement for trachoma elimination: A review of the grey literature. PLoS Negl Trop Dis. 2018;12(1):1-26.

16. GET2020. GET2020 data / Overview epidemiology Country. 2017;(March):2020. Available from: http:// 
www.trachomacoalition.org/sites/default/files/content/ resources/files/GET2020 data Overview epidemiology data sheet_20April2017.pdf

17. Ndayishimiye O, Willems J, Manirakiza E, Smith JL, Gashikanyi R, Kariyo L, et al. Population-Based Survey of Active Trachoma in 11 Districts of Burundi. Ophthalmic Epidemiol [Internet]. 2011 Aug 1;18(4):146-9. Available from: https://doi.org/10.3109/09286586.2011.595 039

18. Ndayishimiye O, Ortu G, Soares Magalhaes RJ, Clements A, Willems J, Whitton J, et al. Control of Neglected Tropical Diseases in Burundi: Partnerships, Achievements, Challenges, and Lessons Learned after Four Years of Programme Implementation. PLoS Negl Trop Dis. 2014;8(5): e2684.

19. Walter SD, Eliasziw M, Donner A. Sample size and optimal designs for reliability studies. Stat Med. 1998;17(1):101-10.
20. Wilson D. Towards a diachronic-synchronic view of future communication policies in Africa. Afr Media Rev. 1989;3:26-39.

21. ISTEBU: Internet. Enquête démographique et de Santé de 2016-2017, Mars 2017. Available at: https:// dhsprogram.com/pubs/pdf/SR247/SR247.pdf

22. République du Burundi ministere de l'interieur Bureau Central du Recensement: recensement general de la population et de l'habitat du Burundi 2008 . Internet - Available from: https://www.usaid.gov/sites/default/ files/documents/1866/2008\%20Burundi\%20Population $\% 20$ Survey_Status $\% 20$ and $\% 20$ Structure $\% 20$ of $\% 20$ Population.pdf.

23. Ramesh, Anita, Julie Bristow, Sari Kovats, Steven W. Lindsay, Dominic Haslam, Elena Schmidt, and Clare Gilbert. "The impact of climate on the abundance of Musca sorbens, the vector of trachoma." Parasites \& vectors 9, no. 1 (2016): 48. 